\title{
The value of technology and of its evolution towards a low carbon economy
}

\author{
Massimo Tavoni • Enrica De Cian • Gunnar Luderer • \\ Jan Christoph Steckel $\cdot$ Henri Waisman
}

Received: 12 February 2010 / Accepted: 13 July 2011 / Published online: 30 November 2011

(C) Springer Science+Business Media B.V. 2011

\begin{abstract}
This paper assesses the economic value associated with the development of various low-carbon technologies in the context of climate stabilization. We analyze the impact of restrictions on the development of specific mitigation technologies, comparing three integrated assessment models used in the RECIPE comparison exercise. Our results indicate that the diversification of the carbon mitigation portfolio is an important determinant of the feasibility of climate policy. Foregoing specific low carbon technologies raises the cost of achieving the climate policy, though at different rates. CCS and renewables are shown to have the highest value, given their flexibility and wide coverage. The costs associated with technology failure are shown to be related to the role that each technology plays in the stabilization scenario, but also to the expectations about their technological progress. In particular, the costs of restriction of mature technologies can be partly compensated by more innovation and technological advancement.
\end{abstract}

\section{Introduction}

Irrespective of all the uncertainties surrounding the science and management of global warming, it is clear that tackling climate change will require a very substantial effort in deploying and developing low carbon technologies. This technology challenge will be very substantial for a wide range of climate stabilization targets, given the heavy reliance of the current energy system on fossil fuels and its low capital turnover. Thus, a profound

G. Luderer · J. C. Steckel

Potsdam Institute for Climate Impact Research, P.O. Box 6012 03, 14412 Potsdam, Germany

M. Tavoni $(\bowtie) \cdot$ E. De Cian

Euro-Mediterranean Centre for Climate Change, Venice, Italy

e-mail: massimo.tavoni@feem.it

H. Waisman

Centre International de Recherche sur l'Environment et le Dévelopment, Paris, France

M. Tavoni $\cdot$ E. De Cian

Fondazione Eni Enrico Mattei (FEEM), Milan, Italy 
reallocation of investments, mostly in the energy sector, will be needed to reduce global emissions and to foster the innovation needed to make low carbon options competitive.

In this context, the socio-economic analysis of climate mitigation has emphasized that there is no silver bullet to solve the climate change problem, and that a broad portfolio of abatement technologies will need to be put into place (Pacala and Socolow 2004, Fisher et al. 2007). In addition, substantial innovation and research has to be undertaken to ensure the development of sustainable mitigation options in the long-term (Schock et al. 1999; Davis and Owens 2003; Nemet and Kammen 2007; Bosetti et al. 2009a).

Given the great uncertainty characterizing the costs and potential of mitigation options, the assessment of the relevance of the various mitigation options and innovation efforts in achieving climate protection is an essential research objective for integrated assessment models. Relaxing the assumption of full availability of technologies is a first step towards the analysis of climate policies in a "second-best" setting. This framework is important to understand the economic value of low carbon technologies and R\&D investments and thus to help design policies that ensure an efficient technology development, also by prioritizing investments in key technological areas.

Thus, it is important that the integrated assessment of climate policies incorporates scenarios and analysis of the value of technology and its change, evaluating the additional economic costs that would be paid if the same climate objective were to be attained without that specific technology -or with constraints on-this technology, be this constraint result from concerns about the ultimate consequences of its large scale deployment or because of "bad news" about its real potential.

The existing literature indicates technology and its change as one of the main driving forces of emissions and a key component of the attainability of climate stabilization. For example, the Energy Modeling Forum 19 (Weyant 2004), a comparative set of analyses of the role of technologies and technology change in climate change policy analyses, showed the transitions required for the implementation of new energy technologies will take time and be costly to implement. Other studies using single models (Kyle et al. 2009; Clarke et al. 2007; Richels and Blanford 2008; Bosetti et al. 2009b; Edenhofer et al. 2010) have been looking at the issue of the option value of technologies and partially this was also the focus of working group 3 of the 4th assessment report of the IPCC (IPCC 2007).

As for technological change, its importance for the economics of climate stabilization has been shown in the literature (Edenhofer et al. 2006; Clarke et al. 2008). The benefits of innovation accrue in the future but need to be financed from the start, raising the policy costs in the early stages of climate policies (Bosetti et al. 2009a, b). Also, innovation is characterized by large uncertainties and specific market failures, and doesn't necessarily decrease the costs of technologies (McDonald and Schrattenholzer 2002).

As a general rule, it is reasonable to expect the value of technologies to be related to their role in the idealized case in which all mitigation options are available. For example, technologies that can be deployed in various sectors and with various fuels, such as carbon capture and storage (CCS), are often found to play an important contribution to carbon mitigation, and thus their failure is likely to be costly. However, a full picture can be obtained only by perturbing integrated assessment models, since many concurrent forces are at play in the choice of the optimal technology mix. Given the wide range of assumptions about the future evolution of technologies, the ideal setting is that of a model comparison exercise, in which coordinated scenarios are run by different modeling teams. This paper is one of the first analyses of this kind, since we carry out a meta-analysis of a set of scenarios simulated by three European integrated assessment models. Model harmonization over the main inputs and over the structure of the technology constraint 
scenarios will allow us to link the value of technologies to the structural characteristics of the models.

Our results indicate that the diversification of the carbon mitigation portfolio is an important determinant of the feasibility of climate policy. As for the economic value of technologies, CCS and renewables are shown to have the highest one, given their flexibility and wide coverage. The costs associated with technology failure are shown to be related to the role that each technology plays in the stabilization scenario, but also to the expectations about their technological progress. In particular, the costs of restriction of mature technologies can be partly compensated by more innovation and technological advancement.

The paper proceeds as follows. In Section 2 we lay out the study design and present the methodology used for the analysis. Section 3 assesses the technological challenge of climate stabilization, and Section 4 evaluates the economic value of few key technologies. Section 5 provides a deep dive on the role of technical change and Section 6 concludes.

\section{Study design}

We begin by briefly summarizing the structure of the model comparison. A complete description of the tools used and of the scope of the analysis can be found in Luderer et al., this issue, and in the report summarizing the RECIPE project. ${ }^{1}$ The model comparison employs three integrated assessment models: IMACLIM-R (Sassi et al. 2010), ReMIND-R (Leimbach et al. 2009) and WITCH (Bosetti et al. 2006), which have been widely used for the assessment of international climate and energy policies.

The models are characterized by a crossbreed approach in which the top-down representation of the macro-economy is matched by an explicit representation of the energy system, including a variety of carbon mitigation technologies. The technological detail doesn't compare to that of bottom-up energy system models (e.g. the MARKAL family), but all models share an explicit foundation in economic theory. An overview of model characteristics is provided in Table 1. IMACLIM is a computable general equilibrium model which is especially suited for capturing the inefficiencies and the associated costs of moving from a fossil fuel based economy to a low carbon one. This is achieved by the partial use of production factors (underused capacities, unemployment) due to sub-optimal investment decisions resulting from the interplay between inertia, imperfect foresight and 'routine' behaviors. ReMIND-R is an optimal growth model with perfect foresight which features a detailed description of energy carriers and conversion technologies. It is designed to characterize investment opportunities in carbon mitigation technologies with substantial accuracy. WITCH is also an inter-temporal optimal growth model, with a focus on the strategic dimension of climate change, and a special emphasis on the role of technological change via diffusion and innovation processes. It is meant to provide the optimal investment response to climate change policies.

An important difference of models is the representation of end-use sectors, and technologies to provide final energy (see also Luderer et al. this issue). An overview of the representation of end-use sectors, energy conversion pathways and key mitigation options are provided in Tables 2, 3 and 4. As a CGE-model, IMACLIM-R is characterized by a high resolution of energy-consuming sectors, with a detailed representation of major supply-side sectors (primary and secondary energies) and end-use sectors (residential, transport, industry). This allows representing the microeconomic rationale behind the

\footnotetext{
${ }^{1}$ Available at http://www.pik-potsdam.de/research/research-domains/sustainable-solutions/research-act-intlclimate-pol/recipe-groupspace/working-papers/recipe-synthesis-report/
} 


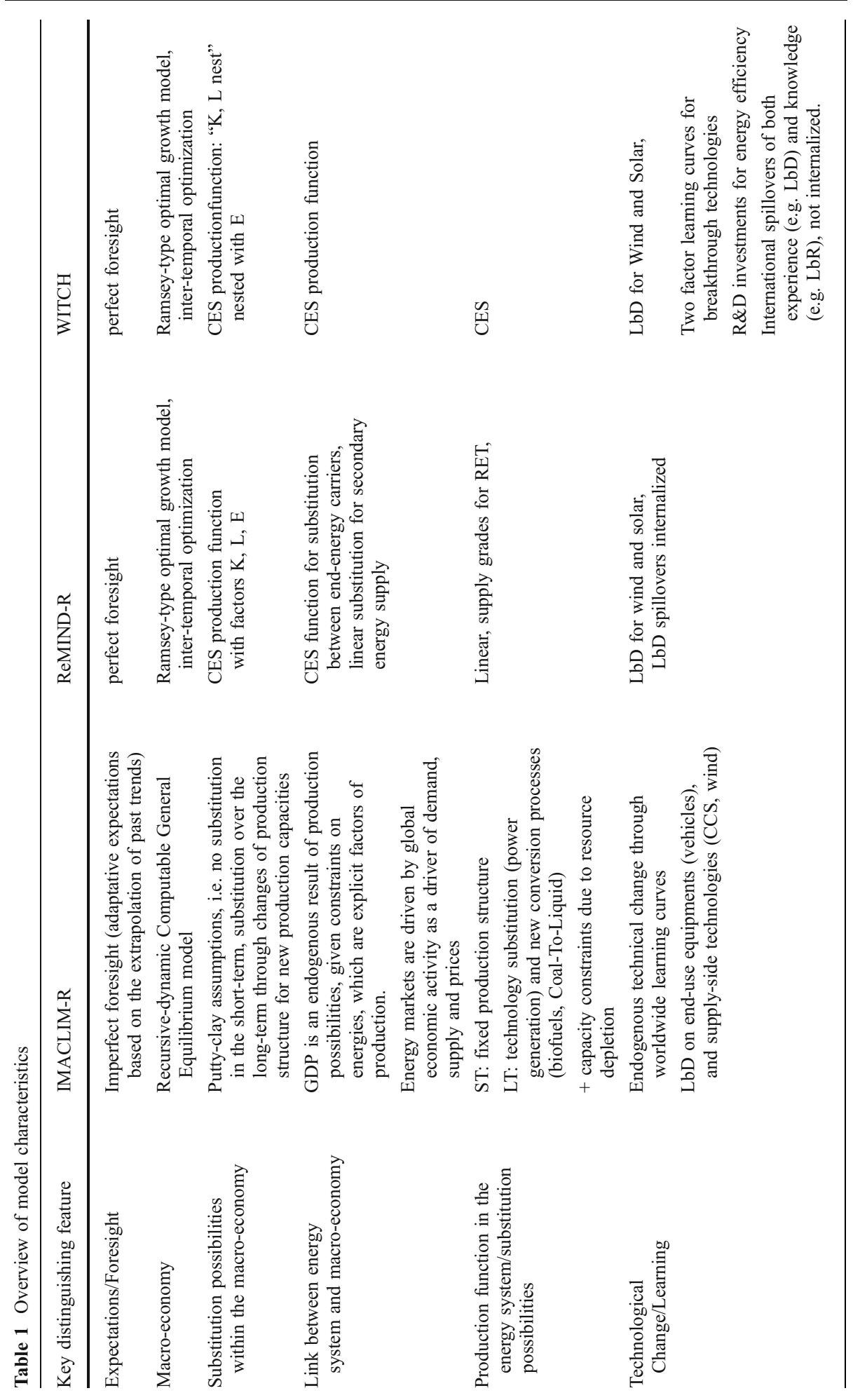




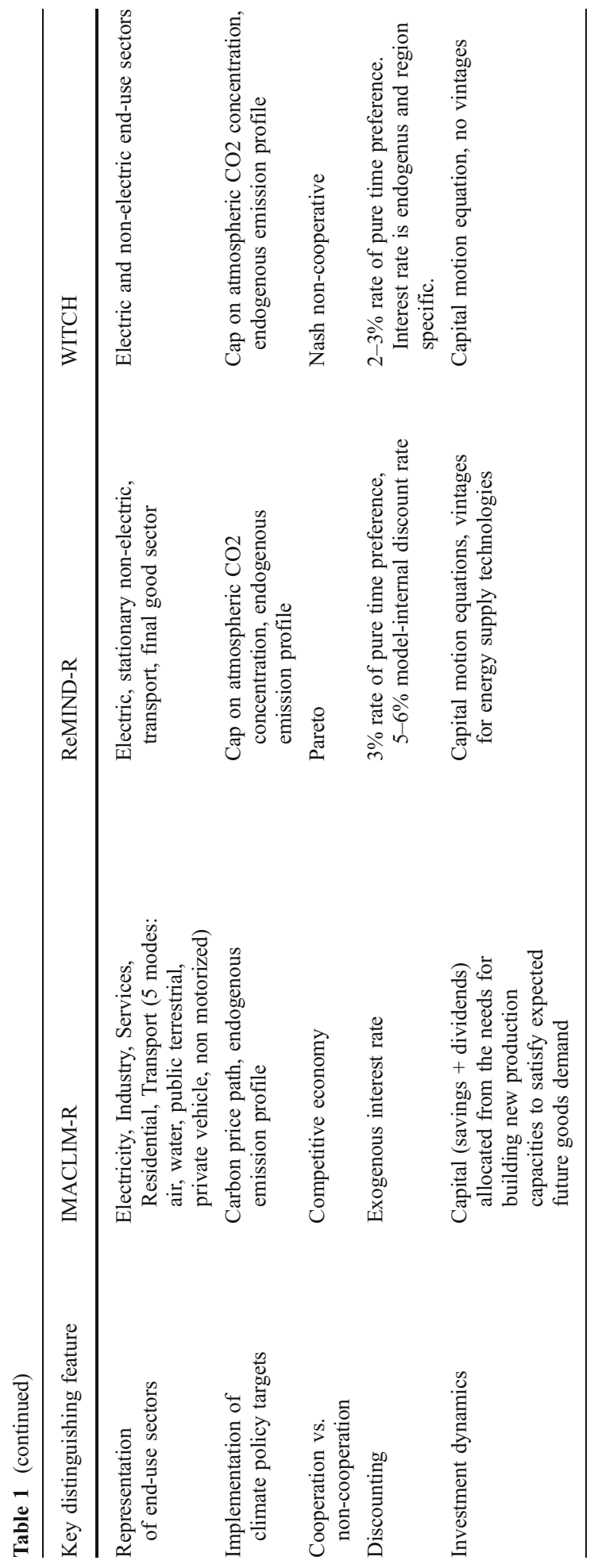


Table 2 Overview of end-use sectors and energy conversion pathways in the IMACLIM-R model

\begin{tabular}{|c|c|c|}
\hline End use sector & Conversion pathways & Key mitigation options \\
\hline Electric & $\begin{array}{l}\text { Conventional coal, gas, oil power } \\
\text { plants; fossil w/CCS; wind, } \\
\text { hydropower; nuclear; }\end{array}$ & Renewables; coal CCS and gas CCS; nuclear \\
\hline Residential & $\begin{array}{l}\text { Provision of gases, liquids, solids } \\
\text { and hydrogen for households }\end{array}$ & Low Energy Buildings, Efficient end-use equipments \\
\hline Transport & $\begin{array}{l}\text { petrol, diesel from crude oil; coal } \\
\text { liquefaction w/and w/o CCS; } \\
\text { biofuels w/o CCS; }\end{array}$ & $\begin{array}{l}\text { More efficient standard cars, Electric vehicles } \\
\text { Switch to biomass as PE carrier, use of CCS for coal } \\
\text { liquefaction; } \\
\text { Modal shift towards low-carbon modes (public } \\
\text { transport, non motorized mobility) } \\
\text { Decrease of (passenger and freight) mobility needs }\end{array}$ \\
\hline Industry & $\begin{array}{l}\text { Provision of gases, liquids, solids } \\
\text { and hydrogen for industry }\end{array}$ & Fuel switching triggered by changes in relative prices \\
\hline
\end{tabular}

adoption of low-carbon technologies described explicitly for power generation (fossil with and without CCS, nuclear, hydro, nuclear, renewables) and passenger transportation (standard, efficient and hybrid vehicles) and implicitly for other sectors (fuel switching triggered by relative energy prices, mimicking technological change). This sectoral resolution also allows capturing sector-specific constraints affecting the diffusion of technical change, like the inertia on the renewal of end-use equipment, the pace of learningby-doing, the technical asymptotes limiting fuel switching and energy efficiency, the sociopolitical obstacles for nuclear, the land-use competition for bioenergies or the availability and efficiency of road and low-carbon transportation infrastructures ReMIND-R and WITCH are, by contrast, more limited in their sectoral representation of end-use sectors. ReMIND-R distinguishes between final energy demand in the stationary sector, and endenergy demand for transport. Secondary energy carriers are considered for energy supply in the stationary sector include electricity, solids, liquids, natural gas, and hydrogen. A large variety of primary energy carriers and conversion technologies are considered for the provision of these secondary energies. Transport fuels can be produced from crude oil, coal (via coal liquefaction) and biomass. Both coal-to-liquid and the liquefaction of lingocellulosic biomass can be combined with CCS.

WITCH distinguishes between electric and non-electric energy demand. In addition to conventional energy sources, one electric and one non-electric backstop technology are

Table 3 Overview of end-use sectors and energy conversion pathways in the ReMIND-R model

\begin{tabular}{|c|c|c|}
\hline End use sector & Conversion pathways & Key mitigation options \\
\hline Stationary (electric) & $\begin{array}{l}\text { Conventional coal, gas, oil power plants; } \\
\text { fossil w/CCS; wind, solar, } \\
\text { hydropower; nuclear; }\end{array}$ & $\begin{array}{l}\text { Renewables; coal CCS and gas CCS; } \\
\text { nuclear }\end{array}$ \\
\hline Stationary(non-electric) & $\begin{array}{l}\text { Provision of gases, liquids, solids and } \\
\text { hydrogen for households and industry }\end{array}$ & $\begin{array}{l}\text { Use of biomass; switch to electricity; } \\
\text { reduction of FE demand }\end{array}$ \\
\hline \multirow[t]{3}{*}{ Transport } & $\begin{array}{l}\text { petrol, diesel from crude oil; coal } \\
\text { liquefaction w/and w/o CCS; }\end{array}$ & Switch to biomass as PE carrier; \\
\hline & biomass liquefaction $\mathrm{w}$ and $\mathrm{w} / \mathrm{o} \mathrm{CCS}$; & switch to hydrogen as SE carrier; \\
\hline & $\begin{array}{l}\text { hydrogen from electrolysis, coal and } \\
\text { biomass gasification ( } \mathrm{w} \text { and w/o CCS) }\end{array}$ & $\begin{array}{l}\text { use of CCS for coal and biomass } \\
\text { liquefaction; reduction of FE demand }\end{array}$ \\
\hline
\end{tabular}


Table 4 Overview of end-use sectors and energy conversion pathways in the WITCH model

\begin{tabular}{llc}
\hline End use sector & Conversion pathways & Key mitigation options \\
\hline Electric & $\begin{array}{c}\text { Conventional coal, gas, oil power } \\
\text { plants; fossil w/CCS; wind, solar, } \\
\text { hydropower; nuclear; biomass. }\end{array}$ & $\begin{array}{c}\text { Renewables; coal CCS; nuclear; } \\
\text { breakthrough electric technology; } \\
\text { energy efficiency. }\end{array}$ \\
Non-electric & Coal, oil, gas, biofuel & $\begin{array}{c}\text { Backstop technology; Energy Efficiency; } \\
\text { Biofuels; REDD }\end{array}$ \\
& & \\
\hline
\end{tabular}

considered, which represent the portfolio of innovative zero-carbon technologies that are yet to be developed. Their cost is modeled to be a function of cumulative deployment and targeted R\&D investments for decarbonization via two factor learning curves. WITCH also considers endogenous $R \& D$ investments into energy efficiency improvements. $R \& D$ is subject to international spillovers, and thus regions can absorb foreign knowledge, though in order to do so they need to invest in domestic R\&D. In addition to the backstop technology, CCS, nuclear, natural gas as well as wind and solar are available as mitigation technologies in the electric sector. For the non-electric sector, advanced biomass is available as additional mitigation option.

For all models, no exogenous constraints or hurdle rates for technology deployment are used, thus the resulting energy mixes are fully endogenous.

To ensure the comparability of results, the models' suite has been harmonized along the most important socio-economic determinants - population and economic growth. Moreover, the models adopted comparable storylines about the availability of fossil fuels, with a general theme of abundant coal and relatively scarcer reserves of oil and gas. The differences in the structure of the models -as for example for the availability and costs of energy technologies- are accountable for the variation in results, which represent different visions of the future.

The models have simulated a climate policy that stabilizes $\mathrm{CO} 2$ concentrations at $450 \mathrm{ppm}$ in 2100 . This roughly corresponds to $530-550 \mathrm{ppm}$ equivalent of all greenhouse gases, which -under a central value for climate sensitivity of 3-translates into an average equilibrium temperature increase of about $2.5^{\circ} \mathrm{C}$ over pre-industrial levels.

In order to investigate the economic value of carbon mitigation technologies, the models have run a set of scenarios characterized by different assumptions about the availability of abatement options. In particular, the following scenarios have been simulated:

- allOptions: benchmark climate policy scenario with full availability of all technology options. This scenario is equivalent to the default $450 \mathrm{ppm}$ scenario presented in Luderer et al., this issue.

- fixNUC: Nuclear power cannot exceed the electricity generated in the baseline scenario.

- fixRET: Renewables based conversion technologies, including biomass and the generic backstop technologies considered in WITCH, are constrained to the baseline level.

- fixBIO: Bio-energy is constrained at the baseline levels.

- noCCS: Carbon Capture and Storage technology is not available.

- noCCS/fixNUC: CCS is not available and nuclear is constrained at baseline.

The set up of the scenarios discriminates those that are deployed even without a carbon policy and those (essentially CCS) that are justified only when a climate target is established. This inevitable bias should be taken into account when assessing the value of the technologies, which for the former will depend on the extent to which the deployment potential is already exhausted in the baseline. The study design also focuses exclusively on 
the supply side, neglecting the role of energy efficiency and savings, which is known to be very significant but which is modeled in a diverse way across models.

Although many different technologies are likely to play an important mitigation role, the technologies restricted in these scenarios are the ones that are believed to host the larger abatement potential within the energy sector, which is the focus of this analysis (IPCC 2007). Some low carbon technologies are deployed, either immediately or in the future, already in the baseline scenario since they are attractive irrespective of the climate problem. This is especially the case for technologies that provide an alternative to the use of resources that are limited by long-term scarcity (oil, gas) and then feature a price increase favoring the diffusion of cheaper energy sources (biofuels and electric vehicles instead of oil-based fuels for transportation; biomass, wind, nuclear power plants instead of gas-fired ones). For others, most notably carbon capture and storage (CCS), their viability rests on the presence of a clear signal that carbon emissions must be limited either through carbon price (improving the competitiveness of low carbon technologies by enhancing the cost of carbon-intensive ones) or other policies and measures imposing their adoption (e.g. norms or standards). Thus, the value of technologies across models depends both on what is foreseen to happen in the presence and absence of a climate policy. As noted above, the models were harmonized on some relevant and exogenous drivers such as the population, economy, and adopted comparable storylines about the availability of fossil resources. However, no attempt was made to align the technoeconomic assumptions for energy conversion technologies, nor the representation of production. This way, the diversity of results reflects the heterogeneous views of the models, thus providing a range of uncertainty within which future stabilization paths are likely to be.

\section{The technology challenge of climate stabilization}

Climate science suggests that the stabilization of the stock of $\mathrm{CO} 2$ in the atmosphere can be directly associated to cumulative $\mathrm{CO} 2$ emissions over the course of the century. In this analysis we contrast a Baseline scenario with one that aims at stabilizing $\mathrm{CO} 2$ concentrations at $450 \mathrm{ppm}$, with each model determining the optimal mitigation profile.

A detailed description of the model's baseline scenarios is provided in Luderer et al. (this issue). In these scenarios, reported in Fig. 1, unabated emissions increase steadily over the course of the $1^{\text {st }}$ half of the century, following trends similar to the historical ones. After mid century, the models projections diverge, reflecting different views of the role of coal and renewables. In IMACLIM-R, increased deployment of coal liquefaction as a surrogate for the

Fig. 1 Absolute $\mathrm{CO} 2$ emissions for the baseline (red) and the stabilization scenario (green), for the three models

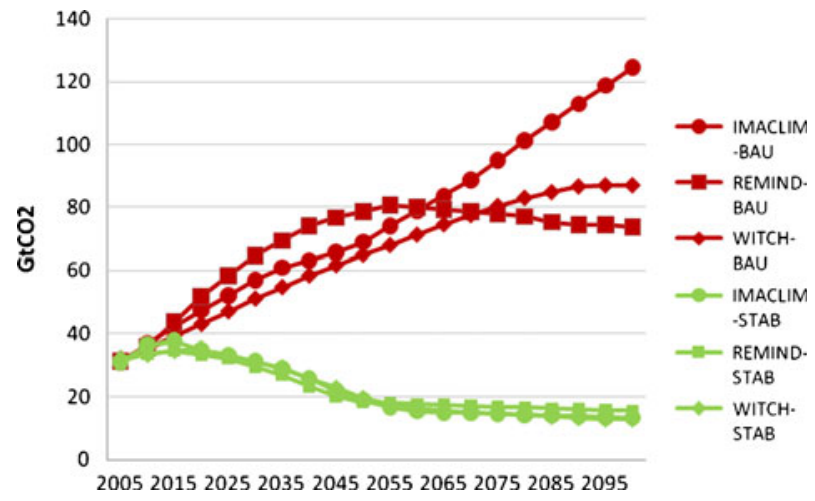


increasingly scarce crude oil leads to an acceleration of emission growth. In ReMIND-R, bioenergy and other renewables become are deployed at significant scale after 2050, thus resulting in a stabilization of emissions. In WITCH, primary energy supply shares remain similar over time, with emissions reaching a plateau in the late part of the century.

On the other hand, stabilization requires a drastic and rapid departure from baseline. Despite the different assumptions about technology, the three models show a very consistent emission reduction pathway, with significant emission reductions materializing already in 2020, and a long term convergence to a subsistence level of 1.5 tCO2 per capita. This reflects the inertia of the energy supply and resilience of the demand, which command in favor of an early action strategy.

Cumulatively, emissions are reduced to at least a third of their baseline levels, as shown in Table 5. Even for a target that falls short of ensuring an average temperature increase below 2 Celsius, as it is the case for the stabilization objective analyzed here, it stands clear that the challenge required is very significant.

As shown in Fig. 2, the three models attain the climate policy with different weights to the supply-side and demand-side dimensions. WITCH and IMACLIM models give a substantial role to lower energy demand and increasing energy efficiency while this effect is less pronounced for ReMIND-R, because a higher energy demand is assumed to be satisfied readily with low-carbon technologies, as a consequence of the model high flexibility in the energy system. All models gradually phase out fossil fuels without CCS, and match the energy demand with low carbon energy sources such as nuclear, renewables, biomass and CCS, though in different proportions.

In order to decarbonize the energy sector to this extent, a significant reallocation of investments needs to be put into place and all models consistently project a significant increase in investment efforts and robustly show that ambitious and cost-effective mitigation requires a rapid switch of investments away from conventional fossil fuels towards low-carbon energy systems (Fig. 3). Investments in fossil energy capacity without CCS are phased out almost immediately (ReMIND-R), within 15 years (IMACLIM) or reduced by more than a factor of ten (WITCH). All models project massive investments in CCS and an up-scaling of investments into renewables. Moreover, according to the WITCH model, R\&D investments are increased to the order of 40 USD billions per year for decarbonisation whereas $R \& D$ investments for energy efficiency roughly double in the presence of a stabilization policy. Total energy system investments are substantially increased with respect to BAU in ReMIND-R, whereas they are comparable in WITCH and IMACLIM. This result is consistent with the finding that, in the presence of a stabilization policy, the WITCH and IMACLIM-R models foresee a pronounced contraction of energy supply (Fig. 2). This result does not emerge from the ReMIND-R model which instead is characterized by a stronger switch in investments from traditional sources to carbon free options, especially CCS and renewables as previously discussed.

In all cases, total energy investments are increasing over time, with the notable exception of the short-term period in IMACLIM during which a threefold mechanism is at play : (1) the short-term amount of capital available for investments is low due to important transitory macroeconomic losses under the climate policy; (2) under imperfect foresight, the

Table 5 Cumulative $\mathrm{CO} 2$ emission (2005-2100) for the baseline and the stabilization scenarios

\begin{tabular}{llll}
\hline & IMACLIM & ReMIND-R & WITCH \\
\hline BAU & 7548 & 6772 & 6430 \\
STAB & 2237 & 2262 & 2229 \\
\hline
\end{tabular}


(a) IMACLIM-R baseline



(d) IMACLIM-R 450 C\&C

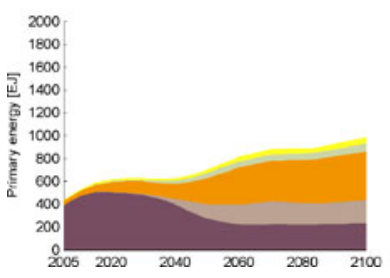

(b) ReMIND-R baseline

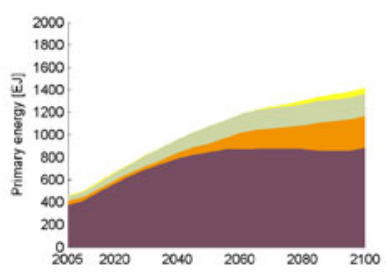

(e) ReMIND-R 450 C\&C



(c) WITCH baseline



(f) WITCH 450 C\&C

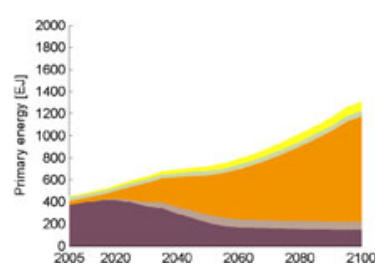

Fig. 2 Primary Energy Supply for the baseline case and the benchmark policy scenario with stabilization of atmospheric $\mathrm{CO} 2$ concentrations at $450 \mathrm{ppm}$

allocation of those investments among sectors is triggered by sectoral demand and the moderation of energy consumption under the climate policy then gives an incentive to slow down the construction of new energy production units and hence to reallocate investments from energy sectors towards non-energy ones; (3) in the short-term period, a major part of new energy production units corresponds to renewable energies. Optimistic assumptions on learning mechanisms for renewable technologies allow a fast decrease of capital costs for those production units during the first years of their diffusion so that low investments are sufficient to ensure the short-term diffusion of those renewable production units.

The feasibility of this investment effort will depend on many factors, which are and will be very uncertain in the near future. The deployment of technologies that are not yet competitive and proven such as CCS, or that are characterized by non-market barriers such as nuclear (and renewables) or that are exposed to technical constraints such as renewables, will face several obstacles. The consequences of technology letdown or failure are explored in the next section.

\section{The value of low carbon technologies}

In this section we analyze the value of low carbon technologies by quantifying the economic costs of the climate stabilization policy under the assumptions about technology availability. We follow the scenarios laid out in Section 2 and explore the consequences of constraints on nuclear, renewables, biomass and CCS. By doing so, we move away from the first best assumption in which models are free to optimally choose the best technology portfolio.

Figure 4 shows how comparing the new mitigation costs to those of the benchmark policy scenario, changes when different technology options are foregone. 
(a) IMACLIM-R baseline

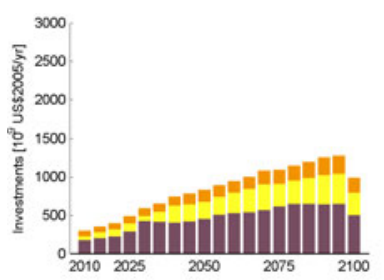

(d) IMACLIM-R 450ppm

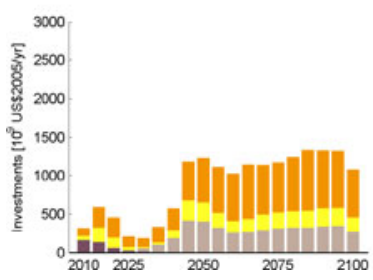

(b) ReMIND-R baseline

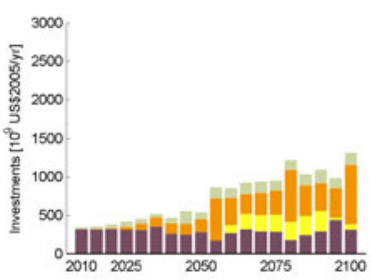

(e) ReMIND-R 450 ppm
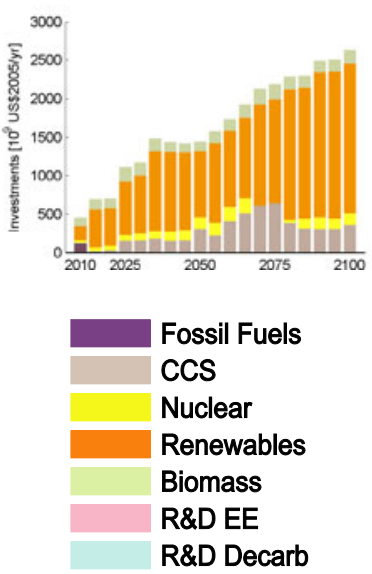

(c) WITCH baseline

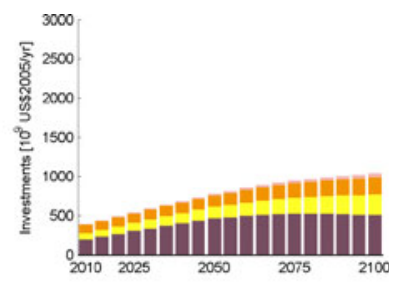

(f) WITCH $450 \mathrm{ppm}$

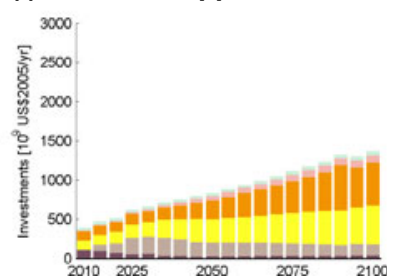

Fig. 3 Investments in the energy system in the stabilization scenario

Despite being characterized by different levels of costs, the models rank the option value of different technology options into two main categories. CCS and renewable energy stand out as the most valuable options. The penalty due to the absence of CCS is low in ReMIND-R, moderate in WITCH, and particularly important for the IMACLIM model. This ranking may seem counter-intuitive when considering Fig. 2, which showed that IMACLIM features a large role of CCS, but not as large as in ReMIND-R. In fact, the higher relative penalty in IMACLIM measures the strategic role that CCS plays in specific sectors of the economy that can only partially move away from the use of fossil fuels due to intrinsic limitations on other energy sources, and are then very difficult to decarbonize without CCS. This concerns in particular power generation and transportation sectors for which fossil fuels cannot but keep

Fig. 4 Economic penalties for scenarios in which the indicated technology option is foregone. Costs are calculated as differences in net present value of global consumption losses (2005-2100), at a $3 \%$ discount rate, with respect to the case of full technology availability

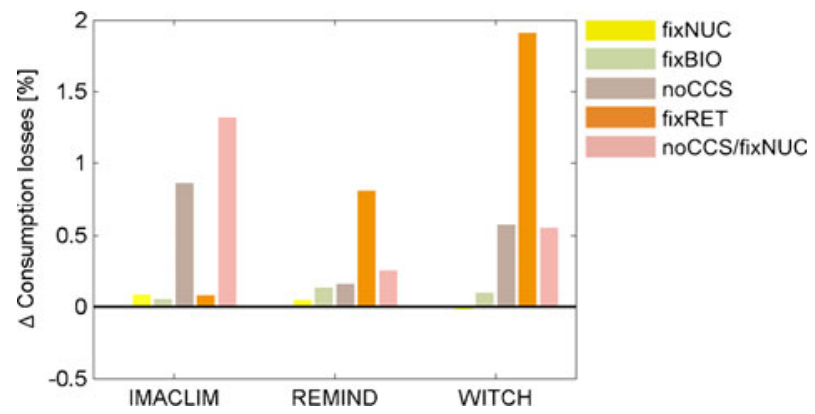


Table 6 Share of $\mathrm{CO} 2$ emissions that are mitigated by CCS in percentage of all mitigated emissions compared to the baseline scenario

\begin{tabular}{lllll}
\hline & All options & fixRET & fixBIO & fixNUC \\
\hline IMACLIM & $11 \%$ & $34 \%$ & $23 \%$ & $23 \%$ \\
REMIND & $23 \%$ & $49 \%$ & $20 \%$ & $25 \%$ \\
WITCH & $11 \%$ & $10 \%$ & $11 \%$ & $11 \%$ \\
\hline
\end{tabular}

an important role since nuclear, renewables and biofuels are constrained by socio-political acceptability, intermittent production and land-use competition respectively.

The importance of CCS is further shown in Table 6 which reports the percentage of the total mitigated $\mathrm{CO} 2$ emissions that are stored by $\mathrm{CCS}$ in the various scenarios. For IMACLIM-R, CCS gains significant importance as soon as any other mitigation option is not or only limitedly available. Particularly when renewable energy is constrained CCS can take some of the additional mitigation burden, a result that can also be found for REMIND$\mathrm{R}$. Compared to the standard policy scenario, CCS plays a lower role in REMIND-R as soon as bioenergy is constrained. This fact can be explained by the resulting constraint on biomass plus CCS, a technology option that is only allowed for in REMIND-R. WITCH does not see an increased role for CCS when other technologies are constrained, mainly due to more restrictive assumptions with respect to available storage.

As for renewables, ReMIND-R and WITCH find that they host the larger option value. For WITCH this result is exacerbated by the fact that the renewables scenario also bans the deployment of the technology breakthrough technologies, which are particularly valuable as a mean to decarbonize the transportation sector. Moreover, renewables are subject to learning in all models, and thus their constraint limits the size of technical progress, an issue we examine in more detail in the next section.

Nuclear and biomass have a less important bearing on the climate policy costs. The result for nuclear is particularly striking, since nuclear power is currently one of the most competitive low carbon options. The reason can be attributed to the fact that, as previously shown, nuclear plays a less important role than renewables and CCS in the climate stabilization scenarios. ${ }^{2}$ In addition, nuclear energy and bioenergy deployment levels in the baseline scenarios are already comparably high in all models, while the deployment level of renewables is significantly increased in the standard policy scenarios (see Table 7). Thus, constraining nuclear energy and bioenergy to their baseline thus naturally leads to lower option values, due to the baseline bias also noticed in the definition of the scenarios.

Summing up, these results confirm that CCS and renewables host the largest potential and value. To put this statement -which has important implications for "technology push" policies such as standards and regulation- into context, it is important to further examine the main determinants of this technology ranking.

The high status of CCS and renewable energy in mitigating carbon emissions can be ascribed to a series of factors. CCS can be applied to mitigation activities in several sectors (transport, power generation, industry). Renewables rely strongly on innovation and experience learning, which implies a relation between the technology option value and the issues of innovation and diffusion processes of new technologies. In addition, renewables and CCS encompass a broad set of mitigation options. Constraining renewables means

\footnotetext{
${ }^{2}$ For WITCH, constraining nuclear actually generates a gain, though a very tight one. The result is due to the backstop electricity generation technology, which in the model is a direct substitute of nuclear. By constraining nuclear the model deploys the advanced technology, which is subject to innovation. Results would be different if we were to think of this advanced technology as advanced nuclear, such as generation IV.
} 


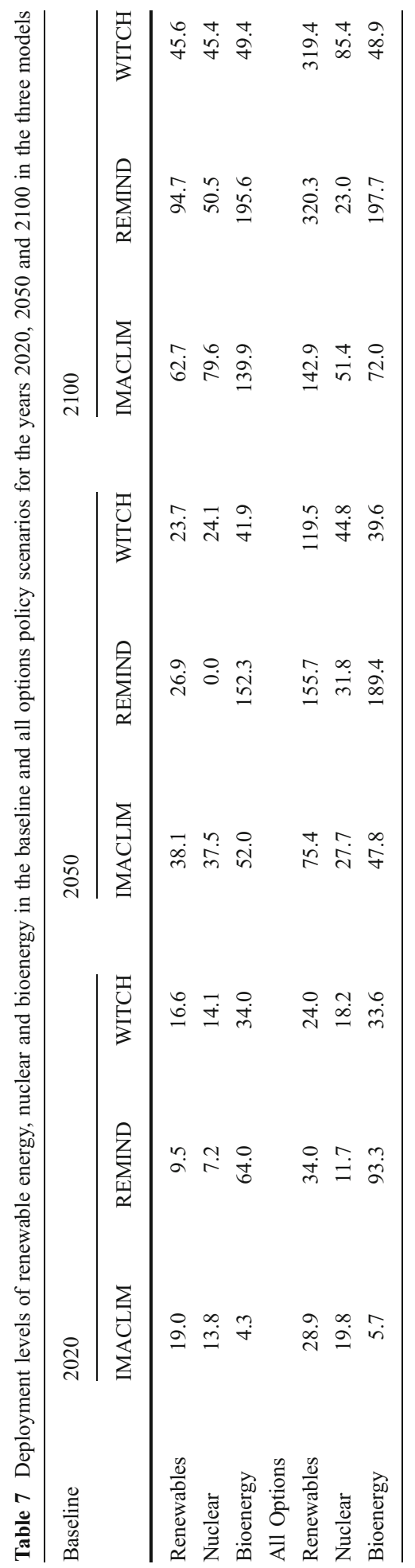


foregoing solar, wind, geothermal, hydro, biomass and generic breakthrough technologies (WITCH model), all at the same time. For ReMIND-R, biomass is a crucial mitigation option for the transport sector. Similarly, the non-electric backstop technology is of paramount importance for the decarbonization of non-electric energy demand in WITCH. CCS can be associated with various fuels (coal, gas, biomass), and can be deployed in different sectors of the economy. In ReMIND-R and IMACLIM, CCS plays a significant role for industry and transport sectors, which are characterized by low mitigation potential and high abatement costs. The role of CCS in transport is especially important in IMACLIM since the major long-term substitute for liquid fuels in the transportation sector is Coal-To-Liquid, which may be an important source of emissions associated to the conversion process in absence of CCS.. Thus, it is not surprising that the value of both options is very significant. Finally, and related to these issues, both these carbon abatement options play a considerable role even when all mitigation technologies are assumed.

In order to single out this effect, in Fig. 5 we plot the penalty of limiting technologies over the benchmark policy scenario, plotted against energy consumption over baseline. The figure reveals a monotonic trend between the role of mitigation technologies in the climate policy and the cost associated with their failure. The upward sloping curves are model specific, with WITCH showing the strongest response due to its generally higher policycosts. For example, the economic penalties are limited when we apply constraints on technologies that are supposed to play a modest role in stabilization over baseline, such as nuclear and biomass. Instead, they become significant for those with a larger mitigation potential: this is for example the case of renewables for ReMIND-R and WITCH, which on average generate $300 \mathrm{EJ}$ of additional energy beyond baseline. Besides playing a large role as emission mitigation technologies, renewables are the technologies subject to endogenous technical change in both models, and thus their foregoing is particularly costly since the positive effect of learning is also lost. For the WITCH model, this is also linked to loss of the breakthrough technology for transportation, a sector characterized by high marginal abatement costs. This suggests a rather complex pattern in which the value of each technology related to the technological evolution in the whole energy sector and the degree of optimism and pessimism about the other candidate technological options.



Fig. 5 Economic penalty of limited technologies' availability as a function of their role in the stabilization scenario. The horizontal axis shows the difference between the average primary energy consumption of a specific energy carrier in the 450 policy scenario and in the baseline. The vertical axis shows the difference of consumption losses between the specific technology-constrained scenarios and the case of full technology availability. Color legend: yellow for nuclear, orange for renewables, purple for CCS, green for biomass 
(a) IMACLIM



(c) WITCH

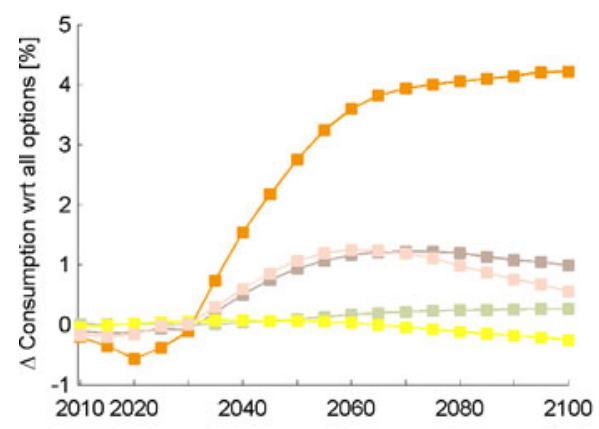

(b) ReMIND-R

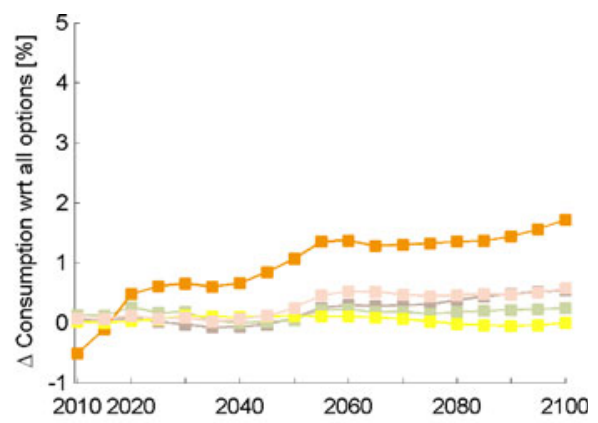

Fig. 6 Economic penalty of limited technology availability over time. Each panel shows all scenarios for each of the three models

We further investigate the option value of technologies by analyzing the evolution of the economic penalties of technology constrained scenarios over time in Fig. 6. Results from IMACLIM point to CCS as the technology with the markedly highest value, especially after 2030; this is the counterpart of the conservatism of this model about bioenergy. In the case of ReMIND-R, renewables have the largest impact from 2020 onwards, though their constraint actually brings some benefits before then, since the large investments required to build the capacity and spark off the learning effect are passed by. As for WITCH, renewables are again shown to host the highest value, because of the technological progress in wind and solar, as well as in the breakthrough technology. Notice, however, that till as long as 2030 this scenario shows an economic benefit, due to the significant investments in $R \& D$ that are needed to make the breakthrough technology competitive in the later decades.

As for nuclear power - one of the few carbon-free, base-load generation technology that is currently deployed at large scale, but which is also the most controversial of all mitigation options - the models indicate it has a rather contained option value. In IMACLIM, intangible costs for nuclear energy are also introduced to monetarize the above mentioned socio-political obstacles and include them in the endogenous competition based on mean costs comparison. The assumption retained in the RECIPE exercise is to keep intangible costs constant over time to represent the inertia in winning the social acceptance of this technology, and the fact that nuclear energy does not provide easy substitutes to oil for liquid fuels (what bioenergy does), which is the crucial challenge of the decarbonisation given the dynamics of the demand for 
mobility. This basically comes down to assuming that the adoption of the climate policy does not improve the acceptability of nuclear energy and explains its lesser role in emission mitigation than renewables and CCS. In the case of WITCH, since a breakthrough technology subject to endogenous technical progress is assumed to replace nuclear power when becoming more competitive, the nuclear constraint generates a loss which is only temporary. The costs would be higher if we were to identify such breakthrough technology as advanced nuclear power, in which case both options would be constrained. In addition, nuclear plays a rather large role in the baseline, and thus the constraint of not exceeding the baseline levels in less strict than for technologies that play a smaller role in the case of absence of climate policy, most notably CCS.

\section{The role of technological progress}

The previous sections have shown the tremendous technology challenge required by climate stabilization and how the economic value of technologies is intrinsically linked to the value of technological progress. This last section is devoted to the discussion of the role of technological change.

The modeling team considered in this paper is suited for this kind of analysis since all three models feature technical change, albeit in a different format. IMACLIM and ReMIND-R assume that low carbon technologies that are not yet mature are subject to learning by doing processes. This is essentially the case in the power generation sector for renewables (e.g. wind and solar), but also for CCS in the case of IMACLIM. As for WITCH, technological change takes the form of both diffusion and innovation processes. Two-factor learning curves are used to model the impact of R\&D investments and of deployment on breakthrough technologies in the power sector and for substitution oil in the transport sector. Learning by doing is assumed to apply to wind and solar. Dedicated R\&D can also increase energy efficiency by substittuing energy demand. Finally, all R\&D investment are subject to international spillovers of knowledge; thus, countries can profit from other countries knowledge stocks, but need to invest in their own in order to build sufficient capacity to absorb.

Technological progress innovation is characterized by market failures which are additional to the environmental ones, such as those related to the limited appropriability of knowledge. Public intervention is thus warranted in order to achieve the economically optimal solution; a stand-alone climate policy for pricing carbon might not ensure a firstbest solution, and specific incentives to foster innovation could have the potential to improve the economic efficiency of climate stabilization (see for example Bosetti et al. 2010 for the case of the WITCH model, that features a game theoretic set up which allows to model multiple externalities). In this context, the costs of constraining a specific mitigation technology might be counterbalanced by an increase in learning and innovation, which could provide some benefits by correcting the innovation market failures.

Indeed, this is what happens in the technology constraint scenarios analysed in this paper. As shown in Fig. 7, the investments in learning technologies tend to increase when the other options are limited. This straightforward substitution effect improves the competitiveness of the technologies subject to learning, for example by lowering their investment costs, and thus ultimately mitigates the additional costs due to technology failure. In the case of the WITCH model, also innovation -measured by R\&D investmentsscales up when relatively mature technologies such as CCS and nuclear are constrained. This generates positive externalities that partly offset the losses, and thus imiplicitly raises the value of innovation prone technologies such as renewables. 


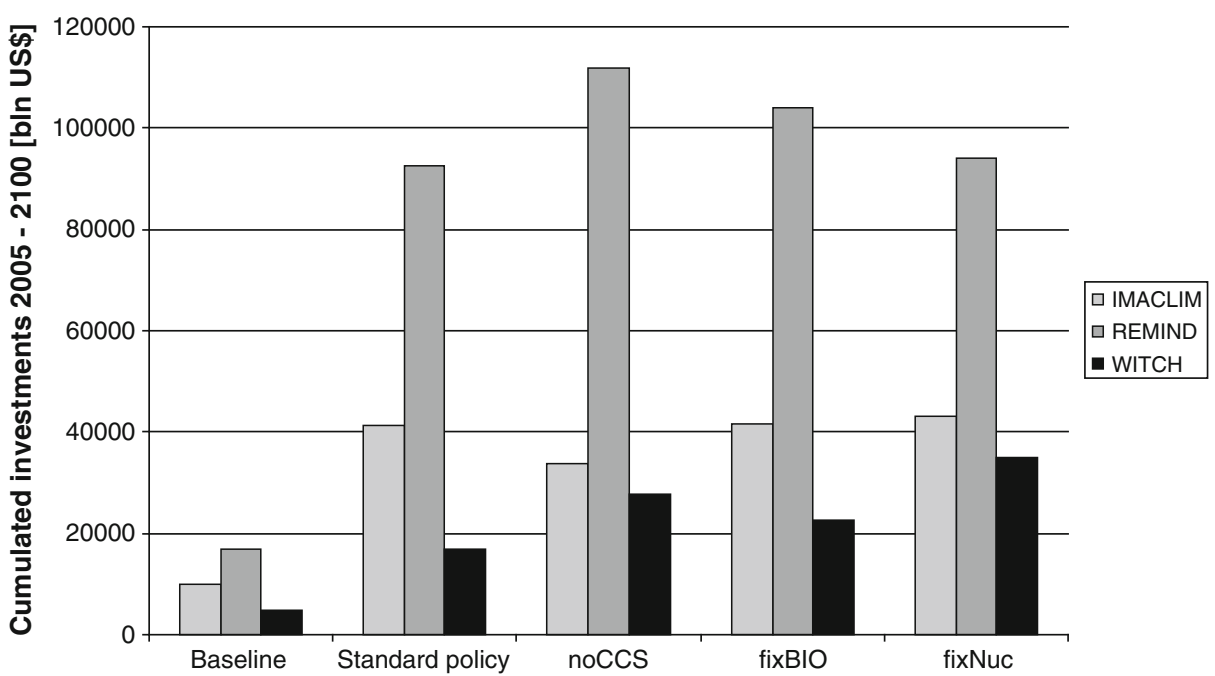

Fig. 7 Investments in learning technologies (renewables) in the various scenarios

However, technological progress is known to be uncertain and difficult to calibrate. For example, historical learning rates offer only partial guidance over the prospect of future progress. To test the robustness of technological change, Fig. 8 presents a sensitivity analysis over the learning parameters in the models. The results show that different assumptions about the rate at which technology will endogenously progress matter for the costs of achieving climate stabilization. The effect is asymmetric, with larger cost increase for low learning rates than cost savings for high parameters. The decresing marginal benefits of learning show that factors other than costs matter beyond a certain level of deployment. For example, istitutional and social barriers limit the speed at which technology -even when competitive- can be deployed.

The magnitude of technogical progress is particulary relevant for the WITCH model, where costs roughly double in the case of low learning. The reason for this strong effect depends on the fact that endogenous technologies can be influenced by both innovation and diffusion activities. A pessimistic assumption about the learning rate means that both processes happen at a lower speed; this is particulary detrimental for innovation in the transportation sector, that in the model calls for substantial investments in energy R\&D.

Fig. 8 Sensitivity of mitigation costs to learning parameters

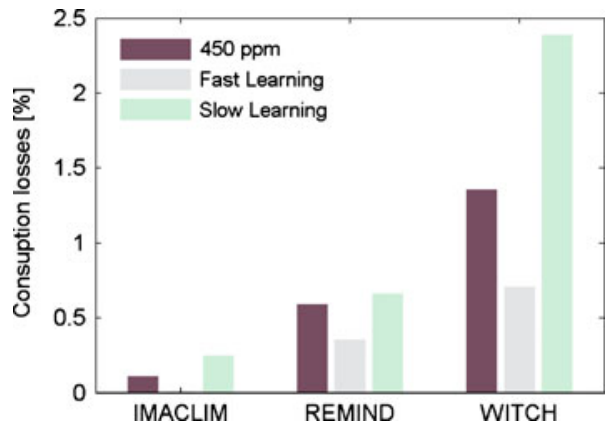




\section{Conclusions}

This paper has focused on the role of technology and its evolution in meeting climate stabilization. By drawing results from a strongly coordinated model comparison exercise, we have shown that the technology challenge to ensure climate stabilization is vast. The key to ensure that the climate objectives are met efficiently will rest on our ability to divert large resources towards building a well-diversified portfolio of mitigation technologies and, at the same time, to generate sufficient innovation and learning.

Our results have indicated that technological constraints that reduce the availability and usage of low carbon technologies can have a significant negative impact on the attainability of climate policy. In particular, CCS and renewables are shown to be the most valuable options, since their flexibility and broad applicability qualify them as the leading mitigation technologies. In this respect, the cost associated with technology failure is shown to be related to the role that each technology plays in the stabilization scenario.

However, other factors, especially the role of technological change, are found to be closely intertwined with that of technological setback. In particular, when innovation market failures are considered, the cost of technology failure of mature technologies might be compensated by more learning and innovation in the ones with higher expectations for technological improvement. Also, the rate at which technology is assumed to be endogenously stimulated has a bearing on the policy costs, especially when R\&D processes are modeled. This result suggests that a successful climate policy needs to support those technologies that have better prospects of technological progress.

The results of the RECIPE model comparison have confirmed some findings of the literature (in particular the role of CCS and renewables), but they have also provided some novel insights (especially for the interplay between technology constraint and progress). However, the analysis is not without limitations. For example, there is an issue of comparability intrinsic in the scenario design: to what extent can we compare a case in which all renewables sources (solar, wind, hydroelectric, biomass, and breakthrough technology) are limited as opposed to a situation in which only nuclear is? How can we value demand management and not only changes in the supply? Since these issues are common to essentially all the analysis carried out so far in this area, they should certainly deserve the attention of future research.

\section{References}

Bosetti V, Carraro C, Galeotti M, Massetti E, Tavoni M (2006) WITCH: a World Induced Technical Change Hybrid Model. The Energy Journal. Special Issue on Hybrid Modeling of Energy-Environment Policies: Reconciling Bottom-up and Top-down: pp. 13-38

Bosetti V, Carraro C, Duval R, Sgobbi A, Tavoni M (2009a) The role of R\&D and technology diffusion in climate change mitigation: new perspectives using the WITCH model, OECD Economics Department Working Papers No. 664, 2009

Bosetti V, Carraro C, Tavoni M (2009b) Climate policy after 2012. Technology, timing, participation. CESifo Econ Stud 55(2/2009):235-254

Bosetti V, Carraro C, Duval R, Tavoni M (2010) What should we expect from innovation? A modelbased assessment of the environmental and mitigation cost implications of climate-related R\&D, mimeo FEEM

Clarke L, Edmonds J, Jacoby H, Pitcher H, Reilly J, Richels R (2007) Scenarios of greenhouse gas emissions and atmospheric concentrations. Sub-report 2.1A of Synthesis and Assessment Product 2.1 by the U.S. Climate Change Science Program and the Subcommittee on Global Change Research. Department of Energy, Office of Biological \& Environmental Research, Washington, DC., USA 
Clarke LE, Weyant J, Edmonds JA (2008) On the sources of technological change: what do the models assume. Energy Econ 30(2):409-424

Davis G, Owens B (2003) Optimizing the level of renewable electric R\&D expenditures using real options analysis. Energy Policy 31(15):1589-1608

Edenhofer O, Lessmann K, Kemfert C, Grubb M, Köhler J (2006) Induced technological change: exploring its implications for the economics of athmospheric stabilization: synthesis report from innovation modeling comparison project. The Energy Journal, Special Issue 2006, 57-107

Edenhofer O, Knopf B, Leimbach M, Bauer N (2010) (eds) The economics of low stabilization. Spec Issue Energy J Volume 31 (Special Issue 1). 2010, in press

Fisher BS, Nakicenovic N, Alfsen K, Corfee Morlot J, de la Chesnaye F, Hourcade J-Ch, Jiang K, Kainuma M, La Rovere E, Matysek A, Rana A, Riahi K, Richels R, Rose S, van Vuuren D, Warren R (2007) Issues related to mitigation in the long term context. In: Metz B, Davidson OR, Bosch PR, Dave R, Meyer LA (eds) Climate change 2007: mitigation. Contribution of working group III to the fourth assessment report of the inter-governmental panel on climate change. Cambridge University Press, Cambridge, United Kingdom and New York, NY, USA

IPCC (2007) In: Metz B, Davidson OR, Bosch PR, Dave R, Meyer LA (eds) Contribution of Working Group III to the Fourth Assessment Report of the Intergovernmental Panel on Climate Change. Cambridge University Press, Cambridge, United Kingdom and New York, NY, USA

Kyle GP, Clarke LE, Pugh G, Wise MA, Calvin KV, Edmonds JA, Kim SH (2009) The value of advanced technology in meeting 2050 greenhouse gas emissions targets in the United States. Energy Econ 31(2): S254-S267

Leimbach M, Bauer N, Baumstark L, Edenhofer O (2009) Costs in a globalized world: climate policy analysis with ReMIND-R. Environmental Modeling and Assessment. Accepted for Publication

McDonald A, Schrattenholzer L (2002) Learning curves and technology assessment. Int J Technol Manag $23: 7-8$

Nemet G, Kammen D (2007) U.S. energy research and development: declining investment, increasing need, and the feasibility of expansion. Energy Policy 35(1):746-755

Pacala S, Socolow R (2004) Stabilization wedges: solving the climate problem for the next 50 years with current technologies. Science 305:968-972

Richels R, Blanford G (2008) The value of technological advance in decarbonizing the U.S. economy. Energy Econ 30(6):2930-2946

Sassi O, Crassous R, Hourcade J-C, Gitz V, Waisman H, Guivarch C (2010) IMACLIM-R: a modelling framework to simulate sustainable development pathways. Int J Glob Environ Issues 10(1/2):5-24

Schock R et al (1999) How much is energy research \& development worth as insurance? Annu Rev Energy Environ 24:487-512

Weyant JP (2004) editor EMF 19: alternative technology strategies for climate change policy. Energy Econ Spec Issue Vol. 26, No. 4, pp. 501-755, 2004 